\title{
SEISMIC DESIGN OF STEEL FRAMES WITH INTENTIONALLY ECCENTRIC INDUCTION-HEAT TREATED STEEL BRACES
}

\author{
Thomas Whittall ${ }^{1}$ and Konstantinos A. Skalomenos ${ }^{2}$ \\ ${ }^{1,2}$ University of Birmingham \\ University of Birmingham, Edgbaston, Birmingham, B15 2TT, United Kingdom \\ e-mail: txw778@student.bham.ac.uk; k.skalomenos@bham.ac.uk
}

\begin{abstract}
Using induction heat treatment to increase the yield stress of one half of a steel brace section as well as inducing intentional eccentricity along the brace length has been experimentally proven to increase the limited post-yielding stiffness exhibited by concentrically braced steel structures. The high-post yielding stiffness and controllability of the brace response through the two material components and eccentricity provides the brace the capability of satisfying multiple displacement performance objectives offering a reduced section size. Design expressions that describe the mechanical behaviour of the bracing system are developed. The seismic performance of steel braced frames using the two-component composite steel braces with intentional eccentricity is investigated and a direct displacement-based design method $(D D B D)$ is proposed in order to support their implementation to building structures. The design method is validated through a verification study performed on the theoretical design of a 4storey office building and seismic performance is assessed through dynamic non-linear time history analysis (NTHA). Time-history analysis results demonstrate that a better control is achieved with the proposed bracing system for achieving drift and ductility limitations.
\end{abstract}

Keywords: Direct Displacement Based Design, Performance Based Design, Concentric Braced Frame, Induction Heating, Eccentricity 


\section{INTRODUCTION}

A new focus on reducing post-hazard financial losses and recovery time, alongside advances in computational methods, has culminated in the emergence of Performance Based Seismic Design (PBSD). Within PBSD, buildings are designed to respond to seismic loading predictably and reliably to various levels of structural performance, increasing hazard resilience [1]. This provides the ability to optimise structures to reduce total life cycle cost and increase sustainability [2]. The poor inelastic behaviour of certain conventional structures has provided difficulties in the reliable prediction of the non-linear response for these structure types [3]. New systems are under development with better controlled inelastic behaviour, providing satisfaction of PBSD with multi-level performance objectives.

In concentric braced frames (CBFs), the poor inelastic behaviour and early buckling of conventional steel braces (CBBs) leads to rapid loss of storey stiffness, large axial deformations, premature brace fracture and deflection of the brace intercepted beam $[4,5]$. The localised inelastic deformations at the plastic hinge leads to a low tangential post-yielding stiffness, resulting in the concentration of residual and maximum drifts. A soft-storey mechanism may be produced, leading to structural instability and collapse in multi-storey buildings [6], observed in the aftermath of large earthquakes, notably the 1989 Loma Prieta [7], Northridge 1994 [8] and Kobe 1995 [9] events. The unfavourable inelastic behaviour of CBBs provides challenges for the application of PBSD with multi-level objectives.

The zero or negative post-yielding stiffness in CBBs leads to the design dominated by the more strenuous objective, leading to an increase in strength demand and larger brace sections [10]. Brace systems that possess and provide control of a large positive post-yielding stiffness will result in improved control of structural performance, a reduction in residual deformations and provide more economical structures through application of PBSD [3]. Several methods have been suggested to increase post-yielding stiffness, such as using reinforcement materials with improved strain hardening behaviour or introducing a secondary parallel inelastic system such as a moment resisting frame in parallel with a CBF [11].

In consideration of the need for alternative brace types, Skalomenos et al. [12] propose a brace with intentional eccentricity (BIE). The steel brace is arranged with end plate connections that provide an intentional eccentricity, producing a trilinear curve in tensile loading with a large post-yielding stiffness. Further to this concept, Skalomenos et al. [13] investigated applying induction-heating $(\mathrm{IH})$ to the BIEs, increasing post-yielding stiffness and ultimate tensile strength, but decreasing ductility. When cyclic loading is applied, Induction-Heated BIEs (IH-BIEs) exhibit large increases in post-yielding stiffness and ultimate tensile strength. By specifying material properties and eccentricity, combinations of the backbone trilinear curves, with differing strengths and post-yielding stiffness can be specified against multi-level seismic design.

In this paper, a force-deformation model of IH-BIEs and the effect of the material properties and eccentric steel section is discussed. A Direct Displacement Based Design (DDBD) method is then proposed for a steel braced frame with IH-BIEs (FIHB) that satisfies multiple performance objectives, each relating to different level of seismic intensity. For validation, a 4storey building is designed using the proposed method and non-linear time history analysis is performed. The results are compared against those of the same frame designed using conventional steel braces to Eurocode 8 [14]. 


\section{INTENTIONALLY ECCENTRIC INDUCTION HEAT TREATED BRACES}

\subsection{Force-Deformation Behaviour}

IH-BIEs comprise a conventional steel hollow member that is induction heated on one half and given a parallel offset from the normal working points of a conventional brace. A rigid brace-to-end gusset plate connection transfers the axial loads from the bracing member to the frame [13]. Figure 1a shows the force-deformation behaviour of a single IH-BIE in tension. A 'first yield' and 'second yield' point, denoted by $P_{y 1}$ and $P_{y 2}$, are observed, corresponding to full yielding of the conventional steel and induction-heat treated steel, respectively. In compression, the brace is assumed to act elastic-plastically, and the compressive strength is taken as $P_{y 1}$. Skalomenos et al. [13] found that the induction-heated steel has a fracture ductility 3 times lower than conventional steel and as a result, yielding of the IH-steel may lead to fracture before $P_{y 2}$ is reached. Therefore, in design, it is proposed that a safety factor is applied to give a lower ultimate tensile strength, $P_{u}$, preventing premature fracture of the brace. Figure 1a demonstrates the safety factor, $\gamma$, defined by relating the point at which the IH-steel yields to the portion of the section remaining elastic. A value of $\gamma$ equal to 0.6 was found sufficient to limit the IH-steel from yielding for an IH-ratio, defined as $F_{y, I H} / F_{y, C S}$, equal to 4 and a value of 0.5 for all values of an $\mathrm{IH}$-ratio below 4 , although this requires verification. The value of this factored ultimate tensile strength is given in terms of $\gamma, P_{y 1}$ and $P_{y 2}$ in Equation 1.

$$
P_{u}=(1-\gamma) P_{y 1}+\gamma P_{y 2}
$$

The design method considers IH-BIEs in a brace pairing, with the maximum storey shear resistance of the brace pair in an inverted- ' $\mathrm{V}$ ' configuration given by the sum of compressive strength, $P_{y 1}$, and ultimate tensile strength, $P_{u}$.
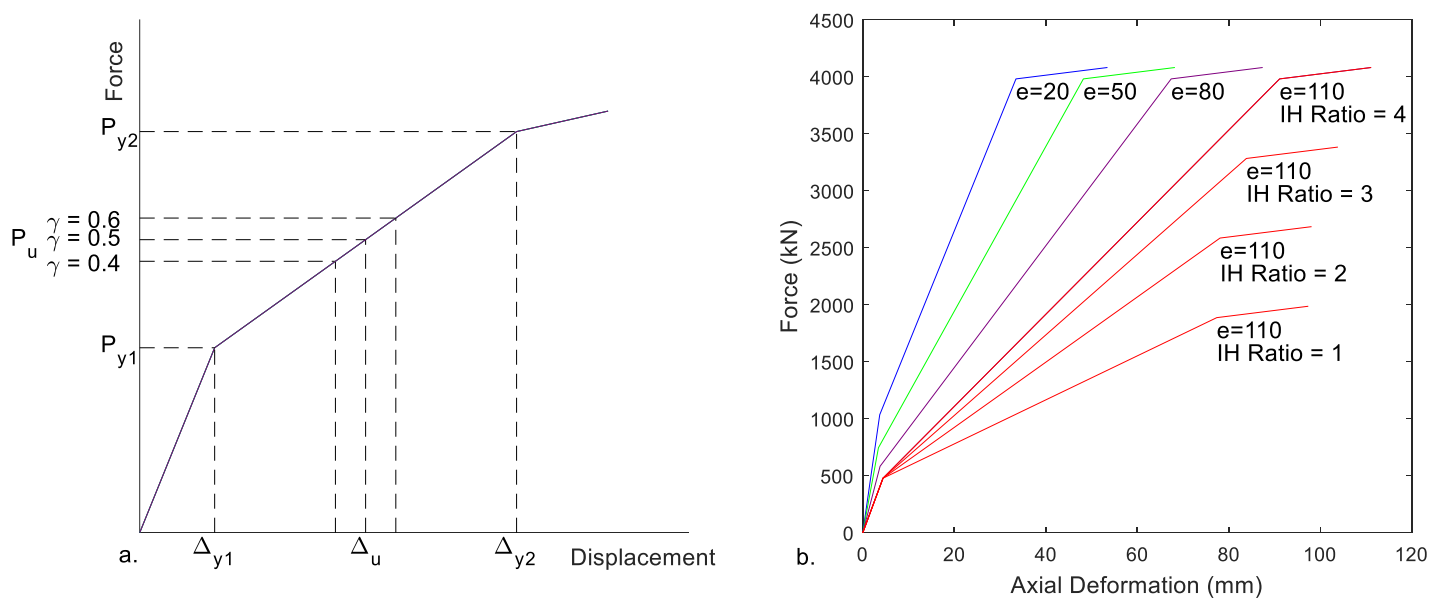

Figure 1: a) Design quantities of a general IH-BIE Member b) Tensile force-deformation behavior of a 244.5 $\mathrm{mm} \times 8 \mathrm{~mm}$ CHS IH-BIE member at differing eccentricities and IH-ratios

\subsection{Effect of eccentricity and induction-heating}

Figure $1 \mathrm{~b}$ shows the effect of the eccentricity and IH-ratio on the idealised behaviour of an $244.5 \mathrm{~mm} \times 8 \mathrm{~mm}$ circular hollow section IH-BIE brace member. As eccentricity increases the brace yields earlier, and $P_{y 1}$, the elastic stiffness, $K_{e}$ and post-yielding stiffness, $K_{i n}$ all decrease, increasing deformation for a given force. $P_{y 2}$ is constant as it is not a function of 
eccentricity. For a constant eccentricity at increasing IH ratios, $P_{y 1}$ and $K_{e}$ are constant, and post-yielding stiffness increases as the induction heat-treated steel remains elastic at greater forces and provides a restoring force to the brace. When combined with the effect of eccentricity, the strain demand on the conventional steel is uniform, preventing a strain concentration that produces local buckling [13]. By varying geometry and material properties a certain controllability of yield points and post-yielding stiffness is afforded, allowing IH-BIEs to be adjustable to satisfy several strength or deformation requirements.

\section{PROPOSED MULTI-LEVEL DIRECT DISPLACEMENT BASED DESIGN METHOD}

The Direct Displacement-Based Design method was selected for the PBSD of FIHBs, since it has been validated for many cyclic force-deformation behaviours [1] and for application in CBFs [15]. DDBD involves the substitution of the MDOF model for an equivalent SDOF system with a secant stiffness and viscous damping that correspond to that of the real structure at maximum displacement response. In the proposed method, the traditional DDBD method is altered so that the satisfaction of two interstorey drift targets relating to different performance levels are achieved by a singular FIHB design, with no significant iterations.

\subsection{Selection of performance objectives}

Two performance objectives relating to the interstorey drift, are first selected by the designer for a 'design' and a 'maximum' performance objective. For the purposes of validating the method, a design interstorey drift limit of $1 \%$ associated with life safety and a maximum interstorey drift limit of $2 \%$ associated with collapse prevention are later assumed and are comparable with drift limits and performance objectives provided by the SEAOC Blue Book [16] and ASCE 41-13 [17] for steel CBFs. The life safety objective is related to the EC8 design seismic action, $10 \%$ probability of exceedance in 50 years (a return period of 475 years), with the collapse prevention objective related to a $2 \%$ probability of exceedance in 50 years seismic action (a return period of 2475 years). In addition, the structure will be checked against a $0.5 \%$ limit for the damage limitation, 'frequent', seismic action, with a $10 \%$ probability exceedance in 10 years (a return period of 95 years).

\subsection{Design and yield displacement profiles}

The selection of a suitable target displacement profile is a key design assumption for translating a MDOF system to a SDOF system and in DDBD methods is generally taken as the first mode inelastic shape of a structure. The high post-yielding stiffness of the FIHB is expected to produce a first mode inelastic displacement profile similar to an MRF due to the prevention of the column-sway inelastic displacement profile that is produced in CBFs. In this method, the equation empirically formulated by Priestley et al. [1] for the normalised first mode inelastic shape of moment-resisting frames is used, given in Equation 2. Further research is required to determine the first mode inelastic shape for FIHBs, but this profile provides a good approximation for FIHBs in preliminary analysis. Two design displacement profiles are calculated, one each for the design objective and maximum objective. The first floor is taken as the critical storey, as it is expected to obtain the highest interstorey drift concentration. The design displacement for the $\mathrm{i}^{\text {th }}$ storey, $\Delta_{i}$, can be found by scaling the first-floor design displacement and is given by Equation 3. This step is undertaken twice, using the interstorey drift once for the design event, giving $\Delta_{i, d}$, and once for the maximum event, giving $\Delta_{i, u}$. 


$$
\begin{gathered}
n \leq 4: \delta_{i}=\frac{H_{i}}{H_{n}} \\
n>4: \delta_{i}=\frac{4 H_{i}}{3 H_{n}}\left(1-\frac{H_{i}}{4 H_{n}}\right) \\
\Delta_{i}=\delta_{i}\left(\frac{\Delta_{1}}{\delta_{1}}\right)
\end{gathered}
$$

Where $n$ is the number of storeys, $\delta_{i}$ is the normalised lateral displacement of the $\mathrm{i}^{\text {th }}$ storey, is the elevation of the $\mathrm{i}^{\text {th }}$ storey and $H_{n}$ is the elevation of the top storey, $\Delta_{1}$ is design displacement of the first storey and $\delta_{1}$ is the inelastic mode shape of the first storey.

IH-BIEs exhibits the 'first yield' point when the conventional steel is fully yielded and can be considered to occur at the same time in compression and tension. The axial deformation of an IH-BIE brace cannot be determined without knowing section properties or eccentricity. Therefore, to avoid incurring a significant number of iterations in the design procedure, the inter-storey drift at yield is assumed to be $0.2 \%$. In the existing experimental tests, IH-BIEs all yielded at approximately $0.2 \%$ interstorey drift [13]. For the purposes of validating the multilevel design method, the braces use the same procedure for the design and maximum displacements, given by Equation 2 and Equation 3, giving $\Delta_{i, y}$.

The design, maximum and yield displacement of the SDOF system and equivalent mass can then be determined by Equations 4-7, using mass and displacement of the $\mathrm{i}^{\text {th }}$ storey, $m_{i}$ and $\Delta_{i}$. In order to calculate the equivalent viscous damping, the displacement ductility of the equivalent system at both the design event and maximum event is found by Equation 8.

$$
\begin{gathered}
\Delta_{y}=\frac{\sum_{i=1}^{n}\left(m_{i} \cdot \Delta_{i, y}{ }^{2}\right)}{\sum_{i=1}^{n}\left(m_{i} \cdot \Delta_{i, y}\right)} \\
\Delta_{d}=\frac{\sum_{i=1}^{n}\left(m_{i} \cdot \Delta_{i, d}{ }^{2}\right)}{\sum_{i=1}^{n}\left(m_{i} \cdot \Delta_{i, d}\right)} \\
\Delta_{u}=\frac{\sum_{i=1}^{n}\left(m_{i} \cdot \Delta_{i, u}{ }^{2}\right)}{\sum_{i=1}^{n}\left(m_{i} \cdot \Delta_{i, u}\right)} \\
M_{e f f}=\frac{\sum_{i=1}^{n}\left(m_{i} \cdot \Delta_{i, d}\right)}{\Delta_{d}} \\
\mu_{d}=\frac{\Delta_{d}}{\Delta_{y}} \\
\mu_{u}=\frac{\Delta_{u}}{\Delta_{y}}
\end{gathered}
$$

\subsection{Equivalent viscous damping and calculation of base shear}

Priestley et al. [1] give an equivalent viscous damping expression for ductile steel frames based on the Ramberg-Osgood hysteretic shape which provides a close fit to that exhibited by FIHBs, given in Equation 9. For the purposes of verifying this method, EVD is not considered critical, and the chosen expression yields satisfactory results. The EVD expression assumes 5\% elastic damping, although steel structures feature a lower level, of $2 \%$. Thus, the expression is calibrated with a correction coefficient based on a numerical study by Grant et al. [18]. Equation 
10 gives equivalent viscous damping using the correction factor $k$, provided by Equation 11. A correction coefficient, $\lambda$, of -0.617 is taken for tangent stiffness damping [1]. The equivalent viscous damping is found using the displacement ductility between yield and design level, $\mu_{d}$, since $\xi_{e q}$ is used to the reduce the displacement spectrum related to the design seismic action of $10 \%$ probability of exceedance in 50 years. Once $\xi_{e q}$ is obtained, the damping correction factor is found by the expression recommended by Eurocode 8 [14] given in Equation 12.

$$
\begin{gathered}
\xi_{\text {steelframe }}=0.05+0.577\left(\frac{\mu-1}{\mu \pi}\right) \\
\xi_{\text {eq }}=\xi_{\text {steelframe }}-k \Delta \xi_{\text {elastic }} \\
k=\mu^{\lambda} \\
\eta=\sqrt{\frac{0.1}{0.05+\xi_{\text {eq }}}}
\end{gathered}
$$

The target period, $T_{\text {eff }}$ can be obtained using the reduced damped displacement spectrum by reading the spectral ordinate at $\Delta_{d}$. The secant stiffness is then calculated with Equation 13, and subsequently the base shear for the design objective using $\Delta_{d}$ in Equation 14 and storey forces using Equation 15.

$$
\begin{gathered}
K_{e f f}=4 \pi \frac{M_{e f f}}{T_{e f f}^{2}} \\
F_{b}=\Delta_{d} \cdot K_{e f f} \\
F_{i}=\frac{F_{b} \cdot m_{i} \cdot \Delta_{i}}{\sum_{i=1}^{n}\left(m_{i} \cdot \Delta_{i}\right)}
\end{gathered}
$$

\subsection{Brace design}

To satisfy both performance objectives, once the design level storey shear is found from the DDBD procedure, the values of displacement ductility at the design and maximum objective, and an assumed value of post-yielding stiffness ratio is used to find a brace section with an eccentricity that satisfies both drift targets. For this procedure, brace sections are considered in terms of brace pairs of an inverted- ' $\mathrm{V}$ ' configuration. The ratio of storey shear resistance between that at yield and design or maximum level is related in Equation 16 to the corresponding displacement ductility, $\mu_{d}$ or $\mu_{u}$, and the post-yielding stiffness ratio, $\alpha$. Figure 2 shows the relationships developed by Equation 16, which allows selection of a suitable brace section.

$$
\begin{gathered}
\Omega_{d}=\alpha\left(\mu_{d}-1\right)+1=\frac{P_{d}+P_{y 1}}{2 \cdot P_{y 1}} \\
\Omega_{u}=\alpha\left(\mu_{u}-1\right)+1=\frac{P_{u}+P_{y 1}}{2 \cdot P_{y 1}} \\
\Omega_{u}=1-\frac{\gamma_{u}}{2} \cdot\left(1-\frac{P_{y 2}}{P_{y 1}}\right)
\end{gathered}
$$




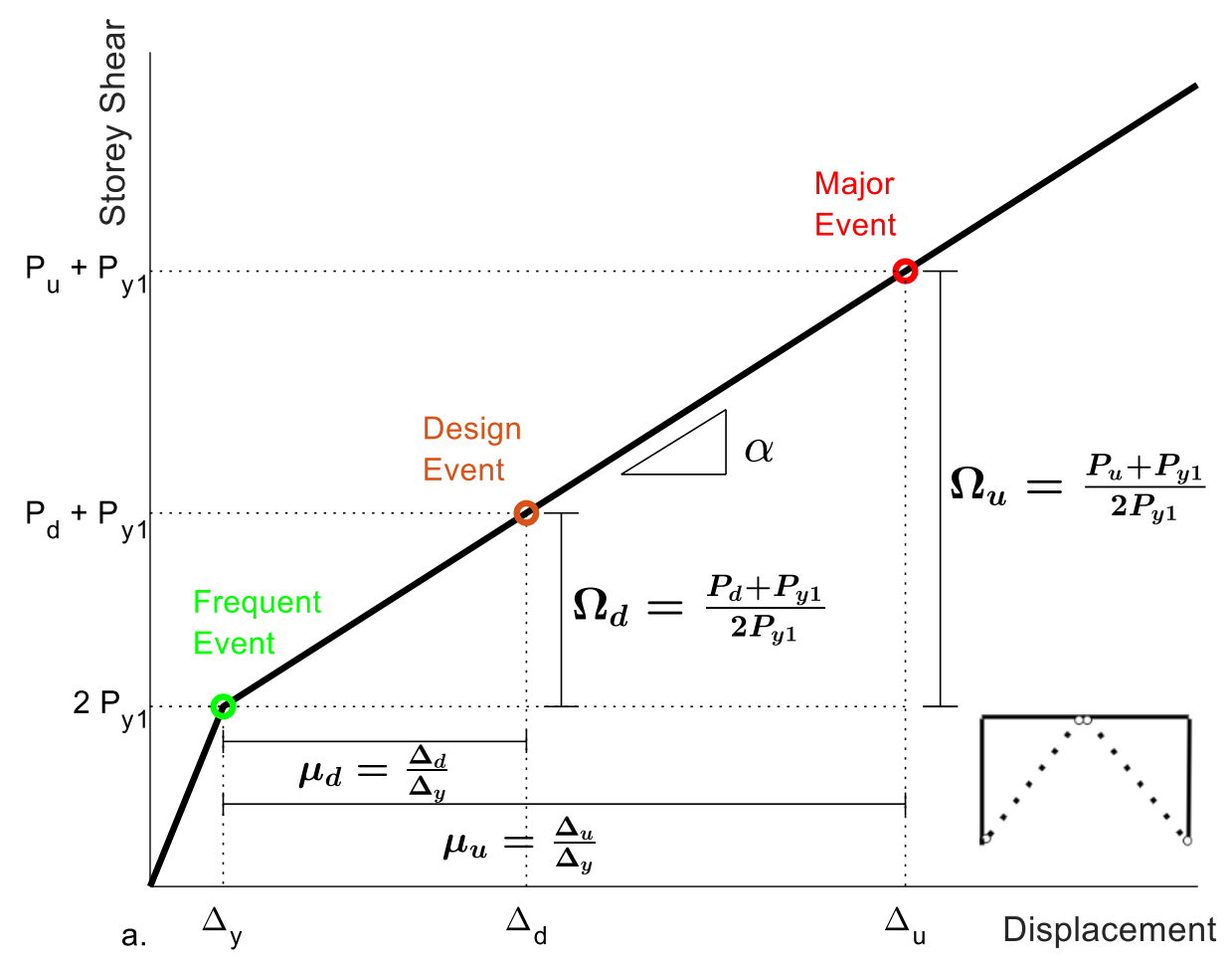

Figure 2: Graph showing the proposed multi-level seismic design and the relationships developed in the proposed design procedure

By using and assumed value for $\alpha$ and the design displacement ductility, $\mu_{u}$, the ratio $\Omega_{u}$ is found using Equation 16. Then, the ratio $P_{y 2} / P_{y 1}$, is calculated using the relationship given in Equation 17, between $\Omega_{u}$ and the parameter limiting maximum tensile strength $\gamma_{u}$. After $P_{y 2} / P_{y 1}$ is obtained, the dimensionless ratio of eccentricity and radius of gyration is then calculated using Equation 18, considering the level of induction heating on the section. Finally, the brace area is calculated using Equation 19 for a given storey shear, $V_{i}$, the calculated $e / r$ ratio and the ratio $\Omega_{d}$, given by Equation 18 . Eccentricity can be determined from radius of gyration in the ratio $e / r$, after brace area has been selected. At this stage, the brace design is checked so that the post-yielding stiffness, $\alpha$, is within $5 \%$ of the assumed value, assuring the required resistance of the brace pair.

$$
\begin{gathered}
\frac{P_{y 2}}{P_{y 1}}=\frac{1}{2} \cdot\left(1+\sqrt{2} \frac{e}{r}\right) \cdot\left[\left(\frac{F_{u, C S}}{F_{y, C S}}\right)+\left(\frac{F_{y, I H}}{F_{y, C S}}\right)\right] \\
A_{r e q}=\left(1+\sqrt{ } 2 \frac{e}{r}\right) \frac{V_{i}}{2 \cdot \Omega_{d}} \cdot \frac{1}{F_{y, C S}}
\end{gathered}
$$

For homogenous dissipative behaviour, the maximum value of storey overstrength at the design level, given by Equation 20, was checked to not differ from the minimum value by more than $25 \%$, to avoid excessive storey shear demand, and the formation of a soft storey mechanism.

$$
\Omega_{i}=\frac{P_{d}+P_{y 1}}{V_{i}}
$$




\subsection{Capacity design rules}

To avoid non-linearity in non-dissipative members, such as beams and columns, capacity design criteria adapted from Eurocode 8 [14] is applied using storey overstrength. The braceintercepted beams are designed for both the gravity loads not considering the diagonals and the unbalanced force, $P_{u b}$, transmitted by the IH-BIE brace pair in an inverted- ' $\mathrm{V}$ ' configuration at the design event seismic action. This is due to the difference in forces transmitted in tension and compression, given by Equation 21. In conventional braces, the effects of flexural yielding and vertical beam deflection from the unbalanced force leads to the prevention of yielding in tension, an increase in ductility demand, and an impairing of the deformation capacity of braces $[5,19]$. To preserve the favourable response of the IH-BIEs in an inverted- ' $V$ ' configuration, the beam to vertical brace stiffness ratio is limited to a minimum of 0.2, given by Equation 22 .

$$
\begin{gathered}
P_{u b}=\left(P_{d}-P_{y 1}\right) \sin \theta \\
K_{F}=\frac{k_{b}}{k_{b r}}=\frac{48 E I_{b} / L_{b}^{3}}{2 K_{e} \sin ^{2} \theta} \geq 0.2
\end{gathered}
$$

Where $P_{u b}$ is the unbalanced force, $P_{y 1}$ is the compressive strength, and $P_{d}$ is the design tensile strength, $k_{b}$ is the flexural stiffness of the beam, given by $\mathrm{E}$, the elastic modulus of steel, $I_{b}$, the second moment of area of the beam, and $L_{b}$, the length of the beam span and $k_{b r}$ is the vertical stiffness of the brace pair given by $K_{e}$, elastic stiffness of the IH-BIEs.

\subsection{Proposed design method flowchart}

Figure 3 shows the design flowchart of the proposed method, showing how the direct displacement-based design and brace design produce an FIHB that satisfies two selected performance objectives.

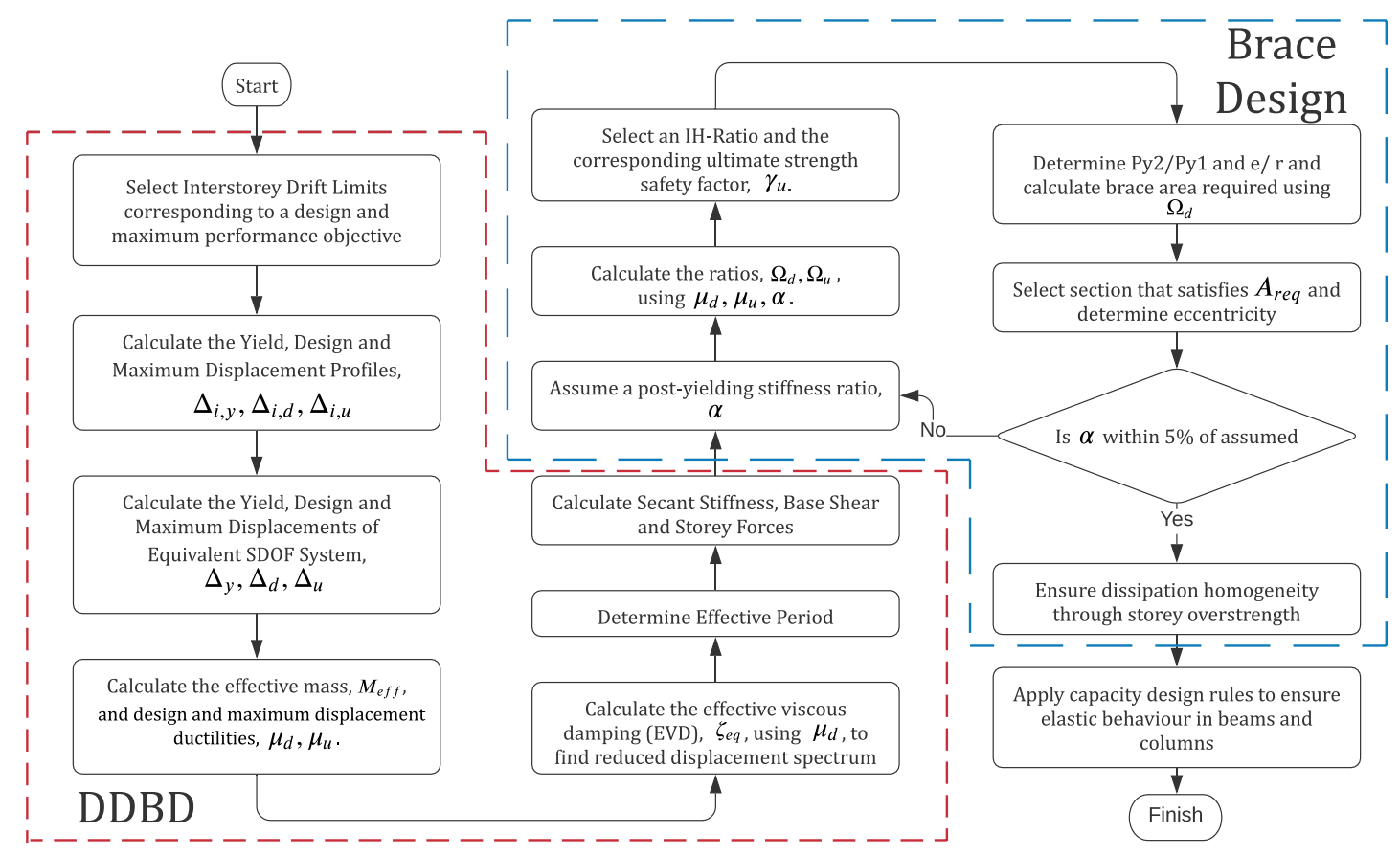

Figure 3: Flowchart of the proposed design method for FIHBs 


\section{VERIFICATION STUDY}

\subsection{Verification case study building}
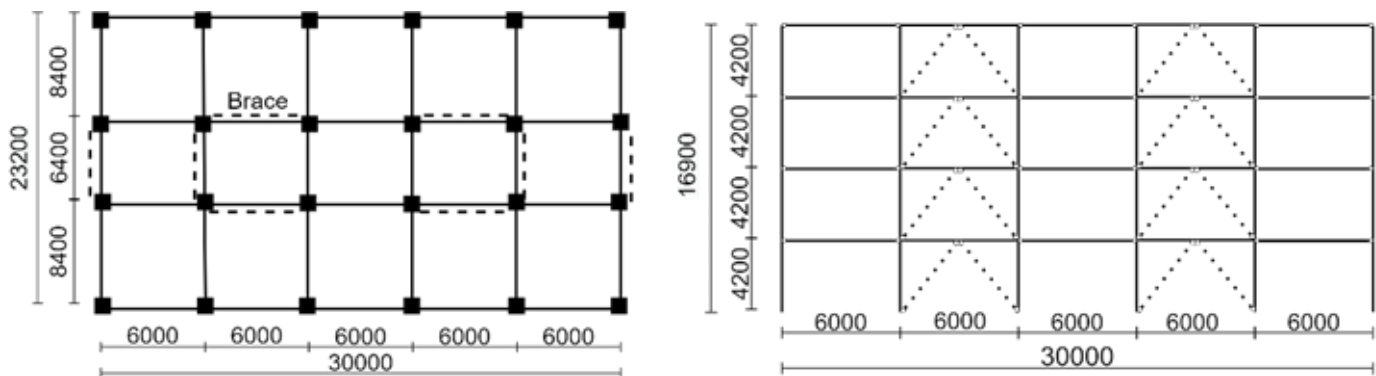

Figure 4: Diagram of a) Floor plan, b) Model elevation plan of the verification study building

A 4-storey mid-rise office building was investigated to verify the proposed design procedure. Figure 4 shows the plans of the 2D frame extracted at the location of the seismic resisting braces in the X-direction, consisting of 2 equally spaced braced bays of 6 metres. An inverted- ' $\mathrm{V}$ ' configuration of the braces was chosen. A constant interstorey height is taken as 4.2 metres and torsional effects are neglected. The frame was designed with conventional braces to EC8 design rules and to the proposed procedure for IH-BIEs, giving two frames in total. The structural design for gravity loads was compliant to EN 1993-1-1 [20]. Permanent and live loads were assumed equal to $5 \mathrm{kN} / \mathrm{m}^{2}$ and $3 \mathrm{kN} / \mathrm{m}^{2}$ at each storey respectively and the cross sections of all members were selected to satisfy Class 1 requirements. All frames were designed for a ground motion with a probability of exceedance of $10 \%$ in 50 years, corresponding to a return period of 475 years, using the 5\% damped acceleration spectrum defined by EC 8 . A peak ground acceleration equal to $a_{g R}=0.35 \mathrm{~g}$, a type B soil, and a Type 1 spectral shape, was assumed. The importance factor, $\gamma_{I}$, was taken as 1, according to EC8 for an ordinary building. The design displacement spectrum was obtained by multiplying the 5\% damped acceleration spectral ordinates by the damping correction factor obtained in Equation 12. Non-linear time history analysis

To perform NTHA, the finite element software framework OpenSees [21] was used to develop a 2D mixed fibre-distributed frame model of the building. The braces were modelled with the induction heating properties on one half, and with a constant eccentricity. Whilst a $2 \mathrm{D}$ frame model, both conventional and IH-BIE braces are modelled in 3D to permit buckling out of plane. To account for second order effects, non-tributary loads were assigned a zero-stiffness leaning column, connected by pinned rigid links. All beam-to-column and columns of the frame are considered pinned, but the braces are fixed, so that only their contribution in resisting the seismic action is considered. The model uses mass-proportional Rayleigh damping, with a damping ratio of $2 \%$, a typical value for steel buildings, and a Newmark acceleration time integration scheme with $\beta=0.25$ and $\gamma=0.5$. A suite of 8 semi-artificial ground motions was considered to perform the NTHA, produced by the Seismic Record Processing program [22]. Existing ground motion histories were modified to fit the targeted EC8 design elastic response spectrum used in the procedure, so the DDBD method could be validated. For the frequent event and maximum event, the ground motions are scaled by a factor of 0.3 and 1.73 , respectively. 


\section{RESULTS}

\subsection{Design summary}

Table 1 gives a brief design summary of the FIHB, giving members at each storey of the braced bay. Brace members were selected to meet the slenderness and material properties of the IH-BIEs experimentally validated against the OpenSees model, to give confidence in the NTHA. The yield strength of the conventional steel is taken as $F_{y, c s}=235 \mathrm{MPa}$, and an IHratio of 4 was selected, giving $F_{u, c s}=940 \mathrm{MPa}$. The post-yielding stiffness of the brace pair was assumed to be $\alpha=0.16$, which was later verified, giving the design ratios of $\Omega_{d}=$ 1.64 and $\Omega_{u}=2.44$. An e/r ratio of 0.73 was found and circular hollow sections (CHS) with an area exceeding the calculated value was selected from the Steel Construction Institute Blue Book [23]. Capacity design was then applied to select the frame members.

\begin{tabular}{r|cccccc|l|l}
\hline \multirow{2}{*}{ Storey } & \multicolumn{5}{|c|}{ IH-BIE Braces } & Columns & Beams \\
\cline { 2 - 8 } & $\mathbf{V}_{\mathbf{i}}(\mathbf{k N})$ & $\mathbf{D}(\mathbf{m m})$ & $\mathbf{t}(\mathbf{m m})$ & $\mathbf{e}(\mathbf{m m})$ & $\mathbf{V}_{\mathbf{r}}(\mathbf{k N})$ & $\boldsymbol{\Omega}_{\boldsymbol{i}}$ & $\mathbf{S 3 5 5}$ & $\mathbf{S 3 5 5}$ \\
\hline $\mathbf{1}$ & 1063.5 & 244.5 & 8 & 60 & 1303.2 & 1.23 & $350 \times 10$ SHS & HEB 500 \\
$\mathbf{2}$ & 957.2 & 244.5 & 7.1 & 60 & 1163.3 & 1.22 & $350 \times 10$ SHS & HEB 500 \\
$\mathbf{3}$ & 744.5 & 219.1 & 6.3 & 55 & 919.8 & 1.24 & $350 \times 10$ SHS & HEB 450 \\
$\mathbf{4}$ & 425.4 & 168 & 5.6 & 40 & 631.3 & 1.48 & $350 \times 10$ SHS & HEB 400 \\
\hline
\end{tabular}

Table 1: Design summary of the FIHB at the braced bay

\subsection{Non-linear time history analysis results}
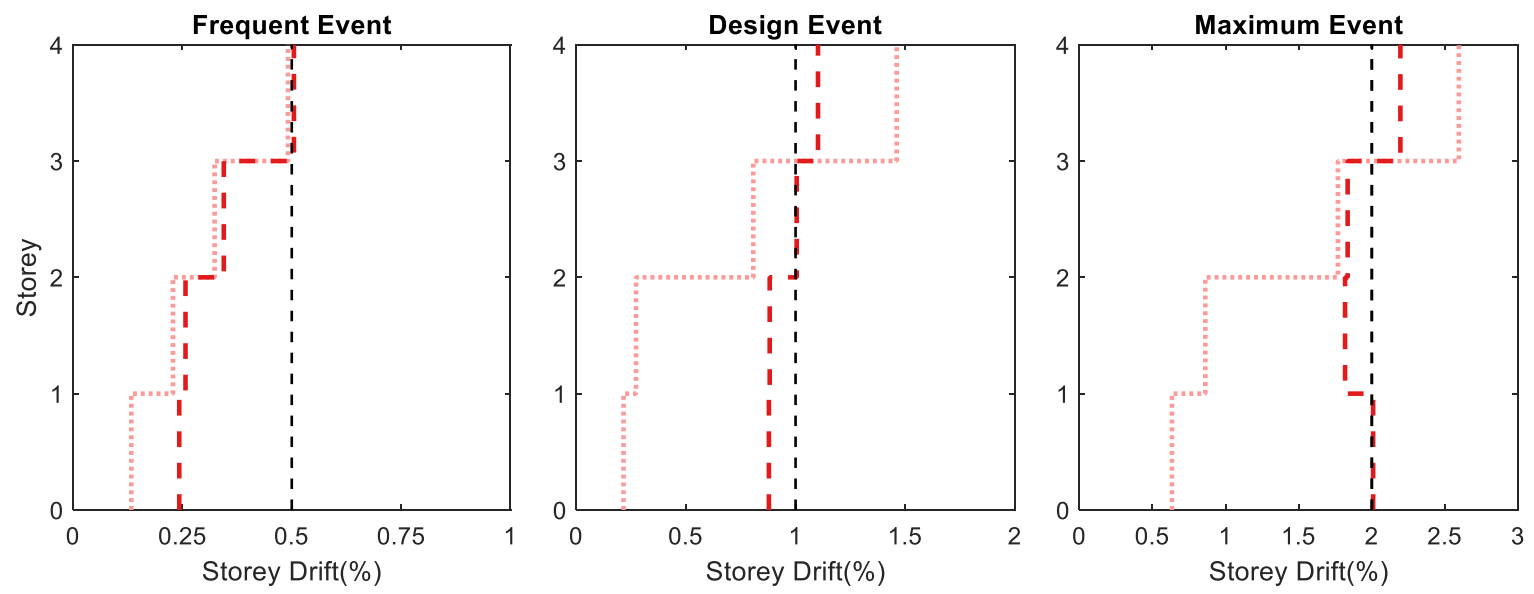

EC8 CBF - - - FIHB - - - Drift Limit

Figure 5: Mean maximum interstorey drift profiles of the FIHB using the proposed method and the CBF designed to EC8

To assess whether the design procedure controlled the response of the FIHB to the chosen interstorey drifts and to compare to a conventionally designed CBF, the mean maximum interstorey drift profiles for both braced frames are given in Figure 5. Both frames compare well against the $0.5 \%$ limit for the frequent event, with each experiencing drift concentration at the top storey. At the design and maximum event, the FIHB exhibits a response typical of a shear building, close to the $1 \%$ and $2 \%$ drift targets, in contrast to the severe cantilever typeresponse observed for the reference $\mathrm{CBF}$. The response of the $\mathrm{CBF}$ designed to EC8 matches existing research $[24,25]$. The results show excellent plastic engagement of the IH-BIE braces, 
with a uniform drift demand, indicating the favourable characteristic of uniform damage distribution, unlike the conventionally designed CBF. The multi-level design method adequately predicts the storey drift demand at both performance objectives, representing excellent performance and satisfaction of the target drifts.

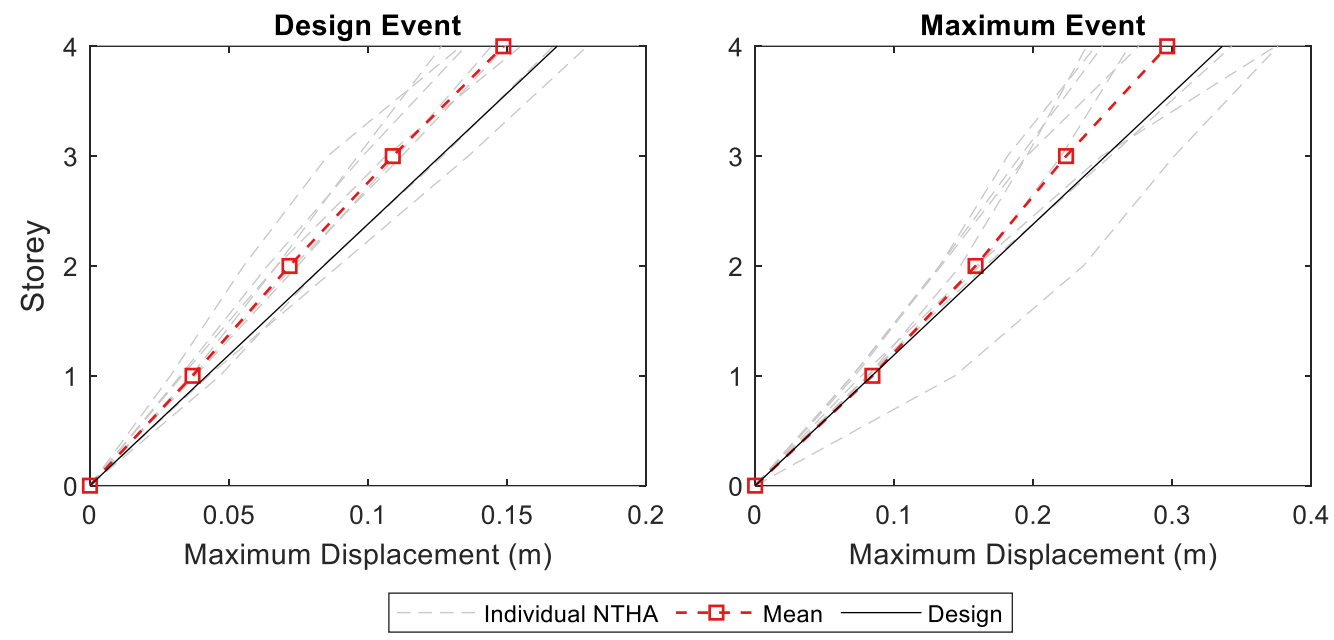

Figure 6: Maximum Displacement Profiles of the FIHBs

The mean and individual NTHA displacement profiles for the FIHB are plotted in Figure 6 against the design displacement profile. The appropriateness of the design displacement profile given in Equation 2 is demonstrated at both the design and maximum event, with only a small difference to the mean displacement profile for both FIHBs. Assumptions made in the DDBD method that the FIHBs provide a similar inelastic first mode shape to steel MRFs are well founded, hence providing an accurate prediction of their behaviour. Further investigation is required to validate Equation 2 for taller FIHBs, with more complex mode effects.
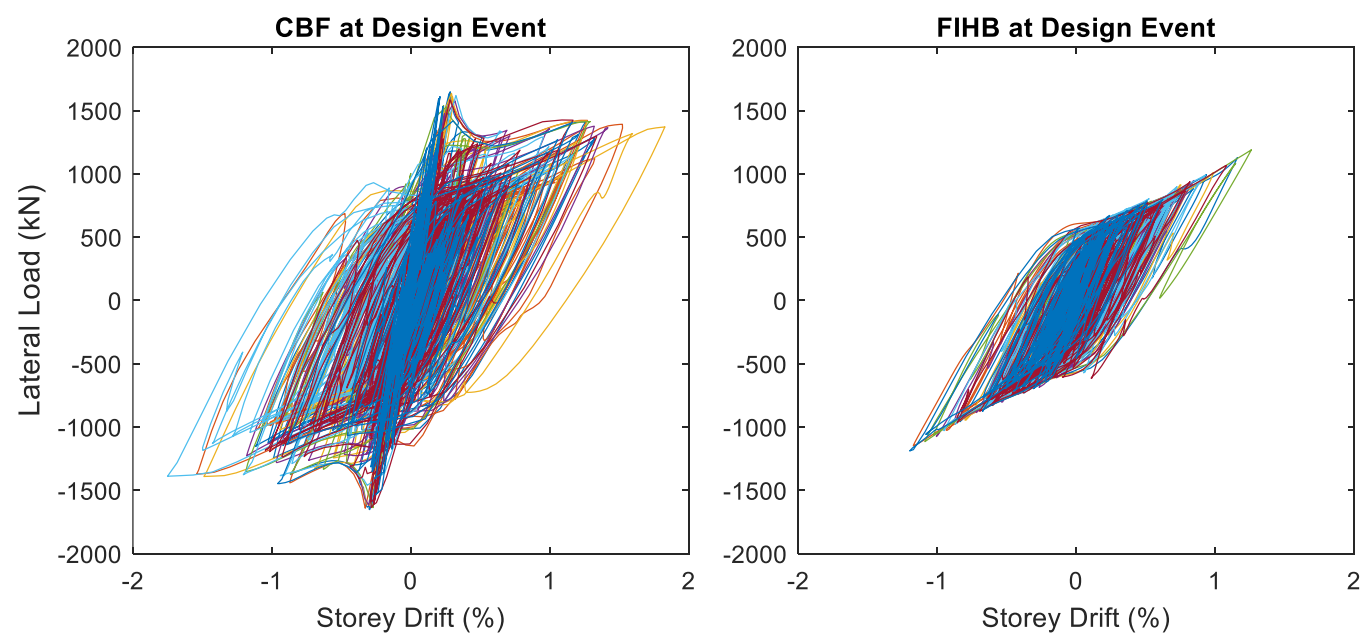

Figure 7: Force-Deformation behaviour of the conventional steel brace pair and the IH-BIE brace pair at the fourth storey at the design seismic action for all ground motions

Figure 7 show the lateral forces in the brace against storey shear drift of the conventional steel braces and the IH-BIEs respectively at the fourth storey, providing the force-deformation behaviour of both conventional steel brace pair and the IH-BIE brace pair system. Compared to a conventional steel brace, which stay elastic at low drifts, the IH-BIE yields earlier at a low 
interstorey drift, as predicted, and dissipates energy. This is congruent with the results of Skalomenos et al. [13], with a more stable hysteretic behaviour found at low seismic intensities. The brace pairing exhibits a stable, and symmetrical response with a large post-yielding stiffness. The hysteretic shape is similar to that based on the Ramberg-Osgood model used in the assumed expression for equivalent viscous damping. Despite the derivation of Equation 9 relating to ductile steel frames, it provides a suitable translation of the energy dissipation between the IH-BIE system in the MDOF structure to that of the equivalent SDOF system.

\section{CONCLUSION}

In this paper, the performance and a new multi-level direct displacement-based design method has been presented for steel braced frames utilising IH-BIEs (FIHBs). The procedure assumes a displacement profile and equivalent viscous damping ratio developed for steel MRFs. Brace design is achieved by relating displacement ductility and a post-yielding stiffness ratio to the storey shears at a design and maximum performance objective, to find a single brace section with a given induction-heating ratio and eccentricity that can satisfy multiple drift targets corresponding to different levels of seismic intensity. To validate the design method, non-linear time history analysis at three different seismic intensities was performed on a 4storey FIHB analytical model using OpenSees. The results indicate that:

- The design method adequately controls the drift demand of the FIHB

- The FIHB satisfies both the $1 \%$ interstorey drift limit at the design performance objective and a $2 \%$ interstorey drift limit at the maximum performance objective, without a design change or significant iteration

- FIHBs exhibit a shear building response and produce a hysteretic shape like that of an MRF, indicating the satisfaction of the assumption of a linear displacement profile and the chosen equivalent viscous damping expression

- The FIHB avoids concentration of drifts compared to a reference concentrically braced frame $(\mathrm{CBF})$ designed to Eurocode 8 and promotes reliable and symmetric dissipation of seismic energy

\section{REFERENCES}

[1] Priestley, M.J.N., G.M. Calvi, and M.J. Kowalsky, Displacement-based Seismic Design of Structures. 2007: IUSS Press.

[2] Welsh-Huggins, S.J. and A.B. Liel, Evaluating multiobjective outcomes for hazard resilience and sustainability from enhanced building seismic design decisions. Journal of Structural Engineering, 2018. 144(8): p. 04018108.

[3] Ye, L., X. Lu, Q. Ma, G. Cheng, S. Song, Z. Miao, and P. Pan. Study on the influence of post-yielding stiffness to the seismic response of building structures. in Proc., 14th World Conf. on Earthquake Engineering. 2008.

[4] Fukuta, T., I. Nishiyama, H. Yamanouchi, and B. Kato, Seismic performance of steel frames with inverted V braces. Journal of Structural Engineering, 1989. 115(8): p. 20162028.

[5] Shen, J., R. Wen, B. Akbas, B. Doran, and E. Uckan, Seismic demand on braceintersected beams in two-story X-braced frames. Engineering Structures, 2014. 76: p. 295-312. 
[6] Ji, X., M. Kato, T. Wang, T. Hitaka, and M. Nakashima, Effect of gravity columns on mitigation of drift concentration for braced frames. Journal of Constructional Steel Research, 2009. 65(12): p. 2148-2156.

[7] Kim, H.I., Seismic evaluation and upgrading of braced frame structures for potential local failures. 1993, The University of Michigan.

[8] Tremblay, R., A. Filiatrault, P. Timler, and M. Bruneau, Performance of steel structures during the 1994 Northridge earthquake. Canadian Journal of Civil Engineering, 1995. 22(2): p. 338-360.

[9] Nakashima, M., Reconnaissance report on damage to steel buildings structures observed from the 1995 Hyogoken-Nanbu (Hanshin/Awaji) earthquake, Abridged English edition. Steel Committee of Kinki Branch, the Architectural Institute of Japan (AIJ), 1995.

[10] Iemura, H., Y. Takahashi, and N. Sogabe, Two-level seismic design method using postyield stiffness and its application to unbonded bar reinforced concrete piers. Structural Engineering / Earthquake Engineering, 2006. 23.

[11] Pettinga, D., C. Christopoulos, S. Pampanin, and N. Priestley, Effectiveness of simple approaches in mitigating residual deformations in buildings. Earthquake Engineering \& Structural Dynamics, 2007. 36(12): p. 1763-1783.

[12] Skalomenos, K.A., H. Inamasu, H. Shimada, and M. Nakashima, Development of a steel brace with intentional eccentricity and experimental validation. Journal of Structural Engineering, 2017. 143(8): p. 04017072.

[13] Skalomenos, K.A., M. Kurata, H. Shimada, and M. Nishiyama, Use of inductionheating in steel structures: Material properties and novel brace design. Journal of Constructional Steel Research, 2018. 148: p. 112-123.

[14] CEN, EN 1998-1 in Eurocode 8: Design of structures for earthquake resistance-Part 1: General rules, seismic actions and rules for buildings. 2004, European Committee for Standardization (CEN): Brussels.

[15] Wijesundara, K.K. and P. Rajeev, Direct Displacement-Based Seismic Design of Steel Concentric Braced Frame Structures. Australian Journal of Structural Engineering, 2012. 13(3): p. 243-257.

[16] SEAOC, SEAOC Blue Book: Seismic Design Recommendations. Structural Engineers Association of California, Sacramento, CA, 2019.

[17] ASCE. ASCE 41-13, Seismic evaluation and retrofit of existing buildings. 2014. American Society of Civil Engineers.

[18] Grant, D.N., C. Blandon, and M. Priestley, Modelling inelastic response in direct displacement-based design. Journal of Earthquake Engineering, 2005. 9(sup2): p. pp.257-278.

[19] D'Aniello, M., S. Costanzo, and R. Landolfo, The influence of beam stiffness on seismic response of chevron concentric bracings. Journal of Constructional Steel Research, 2015. 112: p. 305-324.

[20] CEN, EN 1993, in Design of Steel Structures. 2002, European Committee for Standardization (CEN): Brussels.

[21] McKenna, F., G.L. Fenves, and M.H. Scott, Open system for earthquake engineering simulation. University of California, Berkeley, CA, 2000.

[22] Karabalis, D.L., G.J. Cokkinides, and D.C. Rizos, Seismic Record Processing Program (SRP), Version 1.03, in International Nuclear Information System. 1992, International Atomic Energy Agency: United States. p. 74.

[23] SCI, Steel building design: design data. The Steel Construction Institute and The British Constructional Steelwork Association Limited, 2011. 
[24] Costanzo, S., M. D'Aniello, and R. Landolfo, Seismic design criteria for chevron CBFs: Proposals for the next EC8 (part-2). Journal of Constructional Steel Research, 2017. 138: p. 17-37.

[25] Bosco, M., G. Brandonisio, E.M. Marino, E. Mele, and A. De Luca, $\Omega^{*}$ method: An alternative to Eurocode 8 procedure for seismic design of X-CBFs. Journal of Constructional Steel Research, 2017. 134: p. 135-147. 